\title{
Genetic tools for Sulfolobus spp.: vectors and first applications
}

\author{
Silvia Berkner · Georg Lipps
}

Received: 7 January 2008 / Revised: 14 May 2008 / Accepted: 19 May 2008 / Published online: 10 June 2008

(C) Springer-Verlag 2008

\begin{abstract}
Sulfolobus species belong to the best-studied archaeal organisms but have lacked powerful genetic methods. Recently, there has been considerable progress in the field of Sulfolobus genetics. Urgently needed basic genetic tools, such as targeted gene knockout techniques and shuttle vectors are being developed at an increasing pace. For $S$. solfataricus knockout systems as well as different shuttle vectors are available. For the genetically more stable $S$. acidocaldarius shuttle vectors have been recently developed. In this review we summarize the currently available genetic tools and methods for the genus Sulfolobus. Different transformation protocols are discussed, as well as all so far developed knockout systems and Sulfolobus-Escherichia coli shuttle vectors are summarized. Special emphasis is put on the important vector components, i.e., selectable markers and Sulfolobus replicons. Additionally, the information gathered on different Sulfolobus strains with respect to their use as recipient strains is reviewed. The advantages and disadvantages of the different systems are discussed and aims for further improvement of genetic systems are identified.
\end{abstract}

Keywords Shuttle vector - Knockouts ·

Selectable markers $\cdot$ Archaea $\cdot$ Crenarchaea

Communicated by Erko Stackebrandt.

S. Berkner · G. Lipps

Department of Biochemistry,

University of Bayreuth, Universitätsstr. 30,

95447 Bayreuth, Germany

G. Lipps ( $\square)$

University of Applied Sciences Nordwestschweiz,

Gründenstr. 40, 4132 Muttenz, Switzerland

e-mail: Georg.Lipps@fhnw.ch

\section{Introduction}

The members of the genus Sulfolobus (Brock et al. 1972) belong to the crenarchaeal branch of the archaeal domain. The habitats of these globally distributed thermoacidophilic microorganisms are geothermally active areas where they are found in the aerobic zones of acidic pools and hot springs that are often rich in sulfur compounds. Although for some isolates chemolithoautotrophic growth has been described, the frequently used laboratory strains $S$. solfataricus and S. acidocaldarius seem to have lost this ability (Huber and Prangishvili 2006). These strains grow heterotrophically to high cell densities on organic substrates like tryptone and a variety of sugars with doubling times in the range of 3-6 h during exponential growth and are relatively easy to cultivate in the laboratory. Different Sulfolobus strains have served as model organism for the study of metabolic pathways, transcription, translation and replication (Snijders et al. 2006; Bell et al. 1998; Condo et al. 1999; Duggin and Bell 2006). The structural rigidity of its thermostable proteins has advantages for protein crystallization and also simplifies the purification of recombinant proteins expressed in mesophilic expression hosts by using a heat step.

Complete genome sequences are available for $S$. solfataricus P2 (She et al. 2001), S. acidocaldarius (Chen et al. 2005) and S. tokodaii (Suzuki et al. 2002) and experiments characterizing the transcriptome (Andersson et al. 2006; Lundgren and Bernander 2007) and proteome (Chong and Wright 2005; Snijders et al. 2006; Barry et al. 2006) have been carried out. Consequently, Sulfolobus has developed into an important model organism. Unfortunately, in vivo experiments were for a long time hampered by the lack of appropriate genetic systems for Sulfolobus. Whereas for euryarchaea many genetic tools have been described and 
especially in halophilic archaea interesting and rewarding genetic studies have been undertaken (Sartorius-Neef and Pfeifer 2004; Norais et al. 2007, for a review see Allers and Mevarech 2005), for Sulfolobus the field of genetics has remained unexplored for a rather long period. Several genetic systems have been published in the past 10 years, but often turned out to be not transferable to other laboratories or to require extensive expert knowledge. Only very recently the first genetic tools started to emerge that can be used reproducibly in different laboratories.

The construction of a Sulfolobus vectors requires to takes several components into consideration. First of all a reliable transformation method is a prerequisite for establishing a vector system. If only low transformation efficiencies are achievable, an efficient selection is crucial for vector maintenance.

Furthermore it is important to consider the suitability of different recipient strains. The presence of a restriction/ modification system in a potential recipient strain can efficiently digest the DNA transformed into the organism and therefore prevent successful transformation. Genetic stability is also a problem for some Sulfolobus strains and should be taken into account. For selection techniques that rely on metabolically deficient strains, suitable mutants with low background growth and low spontaneous reversion frequencies are required.

In the first part of the review we recapitulate the methodological basic for the genetic tools in Sulfolobus, i.e., transformation, selection markers, Sulfolobus replicons and recipient strains whereas in the second part we present the available genetic tools.

\section{Transformation procedure}

A reliable transformation protocol is a prerequisite for the development of genetic systems. Sulfolobus can be transformed by electroporation (Schleper et al. 1992). The established protocol is widely used for transformation of Sulfolobus cells with minor changes in different labs. The original protocol uses a Genepulser instrument (BioRad) with $1 \mathrm{~mm}$ cuvettes at $1.5 \mathrm{kV}, 400 \Omega$ and $25 \mu \mathrm{F}$, followed by incubation of the transformed cells directly after the electroporation in growth medium at $75^{\circ} \mathrm{C}$. This protocol was developed for $S$. solfataricus $\mathrm{P} 1$, but it has been applied to other Sulfolobus species and strains (Zillig et al. 1994; Arnold et al. 1999). Aucelli et al. (2006) describe a protocol for $S$. solfataricus $\mathrm{G} \theta$ and $S$. solfataricus $\mathrm{P} 2$ with the same electroporation parameters using a Genepulser Xcell apparatus applying two successive pulses. The same parameters as in the original protocol except for a $2 \mathrm{~mm}$ cuvette also yield highly reproducible transformation results with $S$. solfataricus $\mathrm{PH} 1-16$ and $S$. solfataricus
PBL2025 (Albers and Driessen 2007). A time constant protocol using a Genepulser Xcell with $2 \mathrm{~mm}$ cuvettes and a fixed time constant of $10.2 \mathrm{~ms}$ was also successfully applied for S. solfataricus PBL2025 (Berkner et al. 2007). The most detailed study of different electroporation conditions has been carried out by Kurosawa and Grogan (2005) for S. acidocaldarius. They found that the transformation was successful over a range of different parameters, the most suitable being electroporation in a $1 \mathrm{~mm}$ cuvette at $1,250 \mathrm{~V}, 1,000 \Omega$ and $25 \mu \mathrm{F}$. The authors were also the first to test different regeneration methods, namely the regeneration in normal growth medium as used in the other protocols, regeneration in prewarmed water or regeneration in an alanine/malate buffer solution. Best results were obtained with either of the last two regeneration methods. Incubation in demineralized water for $10 \mathrm{~min}$ at $75^{\circ} \mathrm{C}$ is also suitable for regeneration of $S$. solfataricus (Albers and Driessen 2007).

\section{Transformation efficiencies}

Transformation efficiencies for Sulfolobus solfataricus were first determined with the wild type Sulfolobus spindle shaped virus 1 (SSV1) in a plaque assay and ranged from $4.2 \times 10^{2}$ to $1.1 \times 10^{6}$ transformants per microgram of DNA (Schleper et al. 1992). For the pEXSs vector no exact values are given but it is stated that the transformation efficiencies were in the same range (Cannio et al. 1998). With the pRN1 based vectors $\mathrm{pA}$ to $\mathrm{pN}$ the transformation efficiencies could be directly determined after electroporation (plating after only $30 \mathrm{~min}$ of regeneration on selective medium) in S. acidocaldarius and ranged from $1 \times 10^{2}$ to $6 \times 10^{4}$ transformants per microgram of DNA (Berkner et al. 2007). These values are lower than the values reported for wild type SSV1 but are in accordance to transformation efficiencies determined using constructs for homologous recombination in S. acidocaldarius (Kurosawa and Grogan 2005). From the available data it becomes clear that the transformation efficiencies using the established electrotransformation protocols for Sulfolobus are rather low.

\section{Selectable markers}

In case the transformation efficiency is low, only a very efficient selection procedure is able to build up the high selective pressure needed to extract the low number of transformed cells from the large background of untransformed cells. This ratio can reach $10^{2}$ transformed cells against $10^{8}$ to $10^{10}$ untransformed cells. Vice versa, if the transformation efficiency and transformation frequency are high or high efficiencies are mimicked by a self-spreading system, there is no need for an efficient selection method. 
Therefore, Sulfolobus-Escherichia coli shuttle vectors can follow two strategies. The first strategy is to establish a highly reliable and efficient system for selection, the second way is to circumvent the low transformation efficiencies and frequencies by using self-spreading constructs that are based on infectious viral vector backbones or on spreadable genetic elements (e.g., plasmid-virus hybrids with helper virus or conjugative plasmids). For targeted gene knockouts and for plasmid based Sulfolobus-E. coli shuttle vector only the first strategy can be followed. For this reason the development of selectable markers is the crucial prerequisite for the development of a targeted gene knockout method and for plasmid based Sulfolobus-E. coli shuttle vector systems. In contrast, self-spreading systems are able to operate in the absence of selection.

To achieve a high selective pressure two approaches are possible: first, the use of antibiotics in combination with a resistance conferring enzyme, and second, the use of metabolically deficient mutant recipient strains with inactivated genes and complementation of these mutations by using the intact gene variant as selectable marker gene.

\section{Antibiotic selection}

Antibiotic selection is extensively used in bacteria and a wide variety of resistance conferring enzymes is available for the common mesophilic hosts. However, a reproducible positive selection based on antibiotics is so far not available for Sulfolobus vectors. Reasons for the lack of such a system are stability problems of antibiotics under the growth conditions of Sulfolobus, i.e., $\mathrm{pH} 3$ and $80^{\circ} \mathrm{C}$ and the need for a thermostable resistance conferring enzyme. Although quite a lot of antibiotics have been tested for their effectiveness against Sulfolobus in in vivo and in vitro tests (Cammarano et al. 1985; Grogan 1989, 1991a, b; Sanz et al. 1994; Aagaard et al. 1994; Ruggero and Londei 1996; Cannio et al. 1998; Hjort and Bernander 2001; Bini et al. 2002; Reilly and Grogan 2002) for only two Sulfolobus $-E$. coli shuttle vectors the use of antibiotic selection has been described so far, namely the vectors pAG21 (Aravalli and Garrett 1997) and pEXSs (Cannio et al. 1998; see Table 1). In pAG21 the gene coding for an alcohol dehydrogenase from $S$. solfataricus under control of its native promoter was expressed to confer resistance to butanol and benzyl alcohol in transformed cells (Aravalli and Garrett 1997). In the vector pEXSs the gene coding for hygromycin phosphotransferase from $E$. coli was thermostabilized by errorprone PCR (Cannio et al. 2001). The thermostabilized protein conferred resistance to hygromycin B up to concentrations of $150 \mu \mathrm{g} / \mathrm{ml}$ (Cannio et al. 1998), whereas the MIC of the untransformed wild type was determined to be $100 \mu \mathrm{g} / \mathrm{ml}$ (Cannio et al. 1998). The authors also found this antibiotic to be highly stable under Sulfolobus growth con- ditions (Cannio et al. 1998). These findings, however, have proven to be difficult to reproduce (Jonuscheit et al. 2003). The same group that used the hygromycin selection technique meanwhile developed a new vector system (Aucelli et al. 2006) that works without selection and does not apply the hygromycin selection any more.

Both of the so far published antibiotic selection methods seem to have problems concerning reproducibility. The conditions that have worked in one laboratory are not transferable to another laboratory. This might be due to different cultivating protocols, different medium compositions, different batches of antibiotics used or different handling, and illustrate one crucial problem that hampered the development of reliable genetic tools for Sulfolobus: the development of robust vectors allowing the reproducible and repeatable use in experiments under slightly different conditions.

\section{Uracil selection}

Because of the problems related to antibiotic selection in Sulfolobus other methods of selection were examined. Uracil auxotrophic Sulfolobus strains can be readily isolated using the toxic substrate analogon 5'-fluoroorotic acid (FOA) (Kondo et al. 1991; Grogan 1991a). These mutant strains show mutations in their pyrE or pyrF gene sequences, coding for orotatphosphoribosyl transferase and orotidine-5'-monophosphate decarboxylase, respectively. These two enzymes catalyze the last two steps of the uridine monophosphate de novo synthesis pathway in Sulfolobus (Grogan and Gunsalus 1993). Mutant strains are only able to grow when uracil is supplied at $10-20 \mu \mathrm{g} / \mathrm{ml}$ to their growth medium. As selective medium an uracil free medium is used and the intact pyrEF genes are supplied as selectable marker genes.

This type of selection was first used to demonstrate conjugational marker exchange between different strains of $S$. acidocaldarius (Grogan 1996; Reilly and Grogan 2001; Hansen et al. 2005) and to study homologous recombination in S. acidocaldarius (Kurosawa and Grogan 2005). The first shuttle vector that contained the $p y r E F$ genes from S. solfataricus $\mathrm{P} 2$ under control of their own promoter as selectable marker was pMJ03 (Jonuscheit et al. 2003). In combination with the pyrEF transposon mutant $S$. solfataricus PH1-16 (Martusewitsch et al. 2000) this vector was found to be suitable for uracil selection (Jonuscheit et al. 2003). The pRN1 based shuttle vectors pA-pN (Berkner et al. 2007) also contain the pyrEF genes as selectable marker but in contrast to pMJ03, were not successful in transposon mutants (like S. solfataricus PH1-16) or point mutants as recipient strains. Instead only deletion mutants like S. acidocaldarius MR31 (Reilly and Grogan 2001) proved to be suitable to build up the high selective pressure needed for stable vector maintenance (Berkner et al. 2007). 


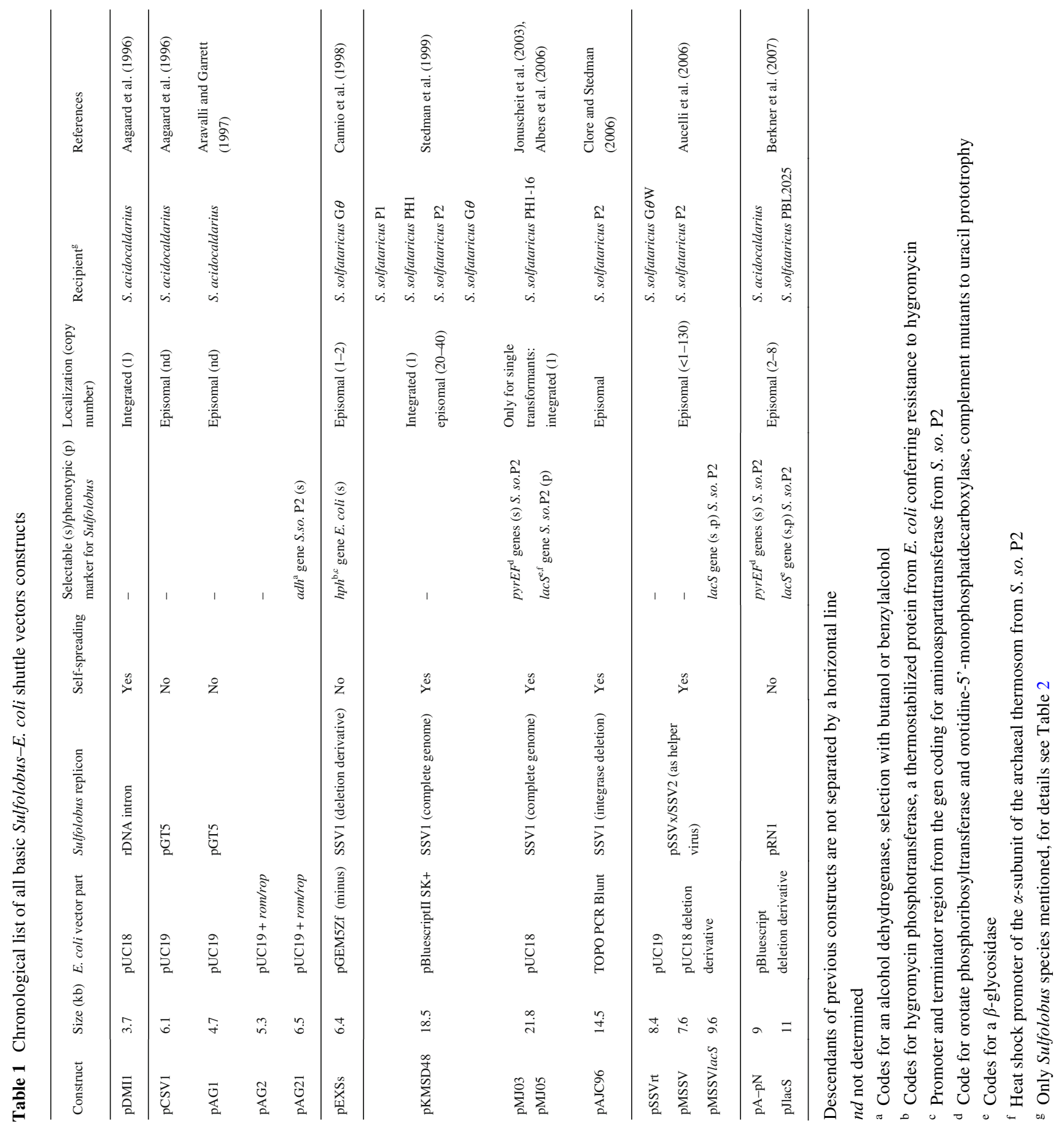




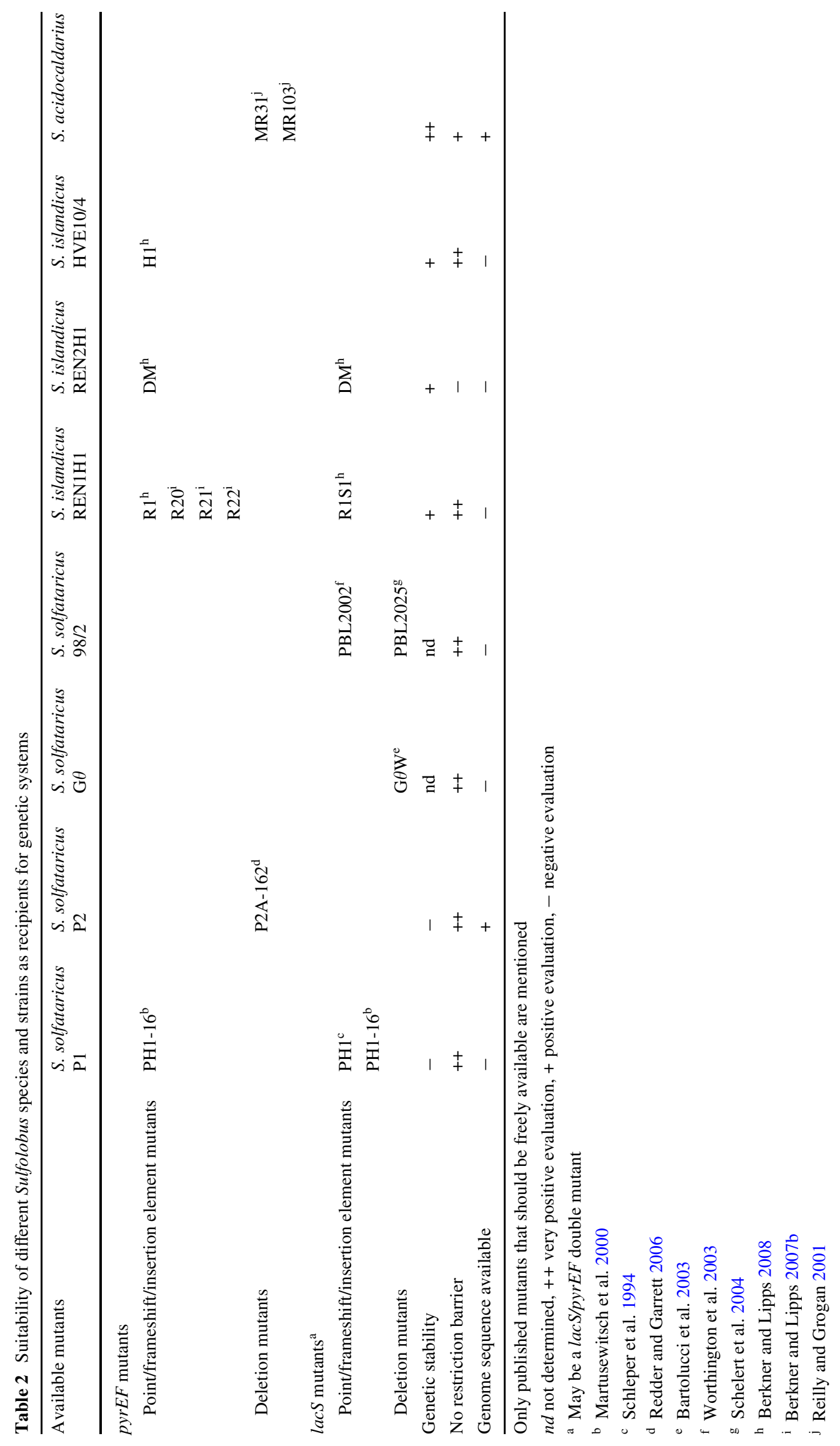


These findings may seem contradictory at first glance but are in fact not contradictory at all. The viral vector pMJ03 does not need selection to spread and replicate in Sulfolobus as shown by the construct pKMSD48 (Stedman et al. 1999), a shuttle vector without a selectable marker. The plasmid based shuttle vectors $\mathrm{pA}-\mathrm{pN}$ on the contrary have to rely solely on selection since they do not spread. For that reason these vectors pose stronger requirements on the stringency of the selection applied.

A fact that further complicates uracil selection is the contamination of essential medium components by traces of uracil. Problems were observed especially for $S$. solfataricus and S. islandicus (Jonuscheit et al. 2003; Berkner and Lipps 2008). Background growth due to uracil contamination of Gelrite and tryptone were observed regularly. However these problems can be circumvented by using other medium components such as NZAmine or single or mixed amino acids instead of tryptone (Berkner and Lipps 2008). It should be noted that the replacement of tryptone is not equally well tolerated by different Sulfolobus strains.

\section{Lactose selection}

The second selection technique relying on the use of metabolically deficient mutants is lactose selection or enrichment. Mutants with an inactivated copy or a deletion of the lacS gene coding for a $\beta$-glycosidase (Cubellis et al. 1990; Grogan 1991b) are unable to grow on a medium containing only lactose as sole carbon and energy source (lactose medium). This form of selection has successfully been applied in S. solfataricus for the development of a knockout system and as selection for shuttle vectors (Worthington et al. 2003; Schelert et al. 2004; Berkner et al. 2007). The host range for this selection technique is limited to $S$. solfataricus and $S$. islandicus, because these two species are able to grow on lactose medium (Worthington et al. 2003; Berkner and Lipps 2008), whereas S. acidocaldarius is not (Grogan 1989; S. Berkner and G. Lipps, unpublished observation). However, also the metabolically more flexible S. islandicus and S. solfataricus first need to adapt to lactose medium and show slower growth rates than in medium supplemented with tryptone. For this reason plating is not feasible directly after electroporation when lactose selection is applied but selection has to be done in liquid medium (Albers and Driessen 2007; Berkner et al. 2007).

\section{Recipient strains}

\section{Genetic stability}

The so far most widely used $S$. solfataricus $\mathrm{P} 1$ and $S$. solfataricus $\mathrm{P} 2$ show only limited genetic stability. For genetic experiments it is problematic that large parts of the genome can be deleted or inverted within a few generations (Redder and Garrett 2006). Mobile genetic elements, that are present at very high numbers in $S$. solfataricus $\mathrm{P} 1$ and $S$. solfataricus P2 (She et al. 2001; Brügger et al. 2002; Brügger et al. 2004) can influence the outcome of genetic experiments, when they are mobilized during the experiment (Schleper et al. 1994; Martusewitsch et al. 2000; Redder and Garrett 2006) and integrate at a different site within the genome.

A measure for the comparison of different Sulfolobus strains is the spontaneous mutation frequency. By selection for uracil auxotrophic pyrEF deficient mutants with the substrate analogon $5^{\prime}$-FOA it is possible to assess the spontaneous mutation rate of the pyrEF genes (Grogan et al. 2001). When comparing so far published mutation frequencies and rates it becomes obvious that there are large differences between different Sulfolobus strains. Apparent mutation frequencies vary by more than five orders of magnitude (Berkner and Lipps 2008) with highest frequencies found in S. solfataricus P1 (up to a fraction of $10^{-4}$ Martusewitsch et al. 2000) and derived strains and lowest frequencies are found in $S$. acidocaldarius and some S. islandicus strains (fraction of $10^{-6}$ to $10^{-8}$, Berkner and Lipps 2008). S. acidocaldarius is so far the only strain that does not contain active insertion sequences (Grogan et al. 2001; Chen et al. 2005), whereas in S. solfataricus isolates (Schleper et al. 1994; Martusewitsch et al. 2000; Redder and Garrett 2006) and in S. islandicus isolates (Blount and Grogan 2005; Berkner and Lipps 2007b) active insertion sequences could be detected. Considering the genetic stability $S$. acidocaldarius is a preferred recipient strain for genetic studies, but also some $S$. islandicus strains show low spontaneous mutation rates.

\section{Restriction/modification activity}

The presence of restriction/modification activity can interfere with the successful establishment of a shuttle construct in the recipient strain. As the transformation efficiencies in Sulfolobus are rather low (see paragraph on transformation efficiencies) it is highly unlikely that unprotected plasmid DNA will overcome a restriction barrier. For that reason it is necessary to examine potential recipient strains for restriction activity. For $S$. solfataricus $\mathrm{P} 1$ and $S$. solfataricus $98 / 2$ and derived strains transformation of unmodified DNA prepared from standard E. coli strains has been shown to be possible (Stedman et al. 1999; Albers and Driessen 2007). S. acidocaldarius contains the restriction enzyme SuaI (Prangishvili et al. 1985; Grogan 2003). From the three examined $S$. islandicus strains REN1H1, REN2H1 and HVE10/4 only S. islandicus REN2H1 was found to contain the restriction enzyme SuiI (Söllner et al. 2006). 
Sulfolobus strains that contain a restriction endonuclease might nevertheless be used as recipient strains if a methylase is available that protects DNA to be transformed into the strains. The restriction endonuclease from $S$. acidocaldarius SuaI is blocked by N4-methylation of the inner cytosine residues within its recognition sequence GGCC (Grogan 2003). The formerly used methylase M.HaeIII methylates the $\mathrm{C} 5$ position instead of the $\mathrm{N} 4$ position and therefore only partially protects DNA from restriction. By using the N4 specific methylase M.EsaBC4I (Grogan 2003; Kurosawa and Grogan 2005) complete protection of DNA from digestion by SuaI can be achieved. The restriction endonuclease SuiI has the recognition sequence GCWGC (Söllner et al. 2006). This sequence can be methylated with the methylase M.TseI. Unfortunately the methylated DNA is not completely protected from restriction by SuiI. So far no N4 specific methylase with the recognition sequence GCWGC is available.

To conclude, most Sulfolobus strains seem to be free of restriction activity or can be used as recipient strains after appropriate methylation of DNA intended for transformation. Only $S$. islandicus REN2H1 contains a restriction activity that can so far not be circumvented by methylation and thus is not a suitable recipient strain for genetic systems.

\section{Host range of Sulfolobus replicons}

When constructing a shuttle vector it is advantageous to use a Sulfolobus replicon that has been shown to replicate in the desired recipient strain. The respective genetic element that is used as backbone for vector construction can certainly replicate in the original host strain, but not always are cured variants of the host strain available. For a range of wellstudied genetic elements from Sulfolobus that have been used for shuttle vector construction, information concerning the host range is available. The virus SSV1 used as backbone for different shuttle vectors has been shown to propagate in $S$. solfataricus $\mathrm{P} 1$ and derived strains, in $S$. solfataricus P2 (Schleper et al. 1992) and in S. islandicus (Arnold et al. 1999) but not in S. acidocaldarius (Schleper et al. 1992). This has been attributed to the lower degree of relatedness of $S$. acidocaldarius to the native host strain of SSV1, S. shibatae, as compared to S. solfataricus (Schleper et al. 1992). Another possibility for the failure of SSV1 to replicate in $S$. acidocaldarius could be due to the restriction activity in S. acidocaldarius. The SuaI recognition sequence GGCC is found 16 times in the SSV1 genome.

For the plasmid-virus hybrid pSSVx and its helper virus SSV2 originally isolated from $S$. islandicus REY15/4 the host range comprises $S$. solfataricus $\mathrm{P} 1, S$. solfataricus $\mathrm{P} 2$ and $S$. solfataricus $\mathrm{G} \theta$ and derived strains (Arnold et al. 1999; Aucelli et al. 2006).
The plasmid pRN1 that was also used for shuttle vector construction was electroporated into $S$. solfataricus $\mathrm{P} 1, S$. solfataricus P2 and S. acidocaldarius. While successful replication has been described for the $S$. solfataricus strains, no replication was observed for $S$. acidocaldarius (Zillig et al. 1994; Schleper 1993). This fact cannot be explained by the restriction activity of SuaI, as pRN1 does not contain any GGCC recognition sequences. Later it turned out that pRN1 is able to replicate in S. acidocaldarius (Berkner et al. 2007). With a member of the $\mathrm{pRN}$ plasmid family being found outside of the genus Sulfolobus (pDL10 from Acidianus ambivalens, Kletzin et al. 1999) it is well possible that the replicon of the pRN family has a broad host range.

From the available information it becomes clear that viral-based vectors have a more restricted host range, as the interactions during infection and possibly chromosomal integration between virus/vector and host seem to pose more stringent requirements on certain features of the host cells. By contrast plasmid-based vectors do only depend on vector/host interactions for the replication of the plasmid and thus might be more suitable to achieve a broad host range.

\section{Knockout systems}

An important tool for genetic experiments is a method to inactivate genes directly in the chromosome of an organism. One way to achieve this is to delete the gene(s) of interest completely or partially from the genome. Although in principle it is possible to isolate desired mutants by random mutagenesis and an appropriate screening procedure, this method is extremely time consuming and only applicable to mutations that produce an appropriately easy to detect phenotype. Therefore methods for targeted gene disruption/gene deletion are very important. For a knockout system an efficient transformation method and a reliable selection scheme are required. The vector does not replicate in Sulfolobus but contains regions homologous to the chromosome in order to recombine site-specifically with the genome.

For Sulfolobus a gene disruption system has been developed by P. Blum and coworkers. Their system uses lactose selection and a lacS insertion sequence mutant (lacS::ISC1217) as recipient strain ( $S$. solfataricus PBL2002 derived from S. solfataricus PBL2000 also named S. solfataricus 98/2, Worthington et al. 2003). Later this host strain been replaced with a spontaneous lacS deletion mutant $S$. solfataricus PBL2025 as recipient strain (58 kb deletion of open reading frames SSO3004SSO3050, Schelert et al. 2004). To obtain knockout constructs, the lacS gene from $S$. solfataricus $\mathrm{P} 2$ under control 
of its native promoter is cloned between two flanking regions (length approximately $700-800 \mathrm{bp}$, Albers and Driessen 2007), that are homologous to chromosomal DNA sequences situated adjacent to the gene or genomic region to be deleted. By a homologous recombination event the lacS gene is integrated into the host chromosome replacing the gene or region to be deleted and restoring the $\mathrm{lac}^{+}$phenotype. Successful mutants are selected for in a medium containing lactose as sole carbon and energy source. After electroporation and regeneration, selection is first carried out in liquid medium ( $0.4 \%$ lactose) before plating on non-selective tryptone/lactose plates. By X-Gal screening (see paragraph on reporter genes) blue colonies that bear the chromosomally integrated lacS gene can be identified. Colonies have to be purified by two to three further rounds of selection, until a PCR reaction with primers binding within the flanking regions yields only one band (Albers and Driessen 2007). Since circular DNA is used for transformation it is currently unclear whether one double or two subsequent single crossover events are involved in the generation of knockout mutants in S. solfataricus.

For S. acidocaldarius no targeted gene knockout has yet been published. However, detailed studies have been undertaken to characterize homologous recombination in combination with conjugational DNA exchange in this organism (Grogan 1996; Reilly and Grogan 2001; Hansen et al. 2005). S. acidocaldarius is capable of efficient homologous recombination using closed circular plasmids, linearized plasmids, PCR products and even short single stranded oligodeoxynucleotides. The test sequences for homologous recombination have been point or deletion mutations in the pyrE gene of different uracil auxotrophic mutants of $S$. acidocaldarius. By recombination with the intact gene variants or partial sequence parts thereof introduced by electroporation, the uracil auxotrophic point or deletion mutants were complemented to uracil prototrophy by efficient recombination between the inactivated genomic copy of the pyrE gene and the exogenously supplied intact sequence. Homologous sequence overlaps down to $10 \mathrm{bp}$ were sufficient for detectable recombination. However the number of $\mathrm{pyr}^{+}$cells obtained increased linearly with the length of the homologous regions up to the longest tested overlap of approximately 250 bp (Kurosawa and Grogan 2005).

For the two other sequenced Sulfolobus strains, i.e., $S$. solfataricus $\mathrm{P} 2$ and $S$. tokodaii, there is to our knowledge no report on successful targeted gene knockouts.

\section{Application of knockout systems}

Currently successful gene knockouts have only been reported for the lacS mutants of S. solfataricus 98/2. Deletion mutants of the $\alpha$-amylase, the mercuric reductase, a repressor and the editing domain of the threonyl-tRNA synthetase as well as deletions of the genes required for bindosome assembly and flagella synthesis were used to study diverse biological question ranging from sugar metabolism, mercury resistance and tRNA editing (Worthington et al. 2003; Schelert et al. 2004; Korencic et al. 2004; Szabo et al. 2007; Zolghadr et al. 2007) and demonstrate the wide applicability of the knockout approach.

\section{Shuttle vectors}

Besides a knockout system, a method for introducing homologous or heterologous genes into an organism is a prerequisite for genetic complementation experiments. Furthermore, shuttle vectors are important tools to (over-) express proteins of interest in the native host, be it for reasons of post-translational modifications or the determination of the localization of the protein in the native host or because the respective protein is difficult to express in functional form in mesophilic expression systems. Therefore shuttle vectors are not only crucial for basic research applications but have also potential for exploitation in biotechnological applications, e.g., for the production of heat stable proteins.

For Sulfolobus the development of shuttle vector systems has lagged behind the developments in other archaea, like for example halophiles or methanogens (see Allers and Mevarech 2005 for a review). The delay was not due to a lack of interest in these vectors but rather a reflection of the difficulties in establishing such as system. Several groups have been working to construct Sulfolobus-E. coli shuttle vectors during the last decade.

The vector itself consists of at least three parts: (1) a replicon for Sulfolobus, (2) a selectable marker for Sulfolobus and (3) an E. coli vector part with an origin of replication and a selectable marker for E. coli.

The current approaches are mainly based on extrachromosomal elements, which have been isolated from different Sulfolobus strains during sampling trips in the 1990s by Wolfram Zillig and coworkers (Zillig et al. 1994, 1996, 1998). These elements can be grouped into three categories: viruses, conjugative plasmids and cryptic plasmids (for reviews see Prangishvili et al. 2001; Garrett et al. 2004; Prangishvili and Garrett 2005; Lipps 2006, 2007). For many of these elements sequence information has been published. However further information from molecular biology or biochemical characterization of the elements exists only sparsely (Lipps 2007). So far no information is available on minimal replicons or origins of replication of crenarchaeal plasmids. Because of this lack of information the shuttle vectors developed so far were almost exclusively based on the complete genome of extrachromosomal 
elements, the only exception being pEXSs (see below and Table 1) that is based only on a part of the virus SSV1 (Cannio et al. 1998). So far the virus SSV1 as well as the plasmid-virus hybrid pSSVx together with the helper virus SSV2 and the cryptic plasmid pRN1 have been used to construct Sulfolobus-E. coli shuttle vectors.

The virus SSV1 was the first known extrachromosomal element from a Sulfolobus strain and has been isolated from S. shibatae (Yeats et al. 1982; Grogan et al. 1990). Many biochemical and molecular biological experiments on transcription, UV-induction, host range, integration into the host chromosome and transformation have been conducted with this virus (Reiter et al. 1988; Schleper et al. 1992; Muskhelishvili et al. 1993; Fröls et al. 2007 for a review see Prangishvili and Garrett 2005). It spreads efficiently in an infected culture and integrates site specifically at a tRNA gene into the host chromosome mediated by a viral integrase, which is partitioned upon integration (Muskhelishvili et al. 1993).

The two other genetic elements from Sulfolobus used as vector backbones so far, the plasmid virus-hybrid pSSVx (Arnold et al. 1999) and the plasmid pRN1 (Keeling et al. 1996), both belong to the pRN family of cryptic crenarchaeal plasmids (Peng et al. 2000) comprising additionally pRN2, pHEN7 and pDL10 (Keeling et al. 1998; Kletzin et al. 1999). The plasmid pRN1 is the best-studied archaeal plasmid. It has been isolated from $S$. islandicus REN1H1 (Zillig et al. 1994) and is natively found together with pRN2 in its host strain but is able to replicate independently (Purschke and Schäfer 2001). The transcription, the copy number and the regulation of its replication operon have been examined (Berkner and Lipps 2007a) and the three conserved proteins Orf56, Orf904 and Orf80 have been studied biochemically (Lipps et al. 2001a, b, 2003; Beck and Lipps 2007) and the structure of the primase domain of the multifunctional replication protein Orf904 has been solved (Lipps et al. 2004).

Given the lack of an understanding of the Sulfolobus replicons it was crucial for the development of the Sulfolobus shuttle vectors to interrupt the replicon at different positions. Therefore in order to minimize the risk of choosing a interruption site within a region that is important for replication or stability of the shuttle vector constructs, random interruption at different sites was used for the SSV1 based shuttle vectors (Stedman et al. 1999) as well as the pRN1-based shuttle vectors (Berkner et al. 2007). The different interruption constructs for the SSV1 constructs were obtained by ethidium bromide mediated partial restriction of SSV1 DNA with Sau3AI and subsequent selection for shuttle vectors that retained the ability to replicate and to infect host cells in $S$. solfataricus P1. For the pRN1 based vectors a Tn5 derived transposon (Agron et al. 2002) was used to generate different interruption sites within the pRN1 plasmid.
Chronological overview of published Sulfolobus-E. coli shuttle vectors

The first Sulfolobus-E. coli shuttle vector was described in 1995 by Aagaard et al. A mobile rDNA intron from Desulfurococcus mobilis (Aagaard et al. 1995) was combined with the $E$. coli vector pUC18 and named pDM1. Another vector from this group, pCSV1, was based on the plasmid pGT5 from Pyrococcus abysi. To reduce the instability observed for this construct, the rom/rop gene was added to the vector to lower the copy number in E. coli (Aravalli and Garrett 1997). Additionally an alcohol dehydrogenase was cloned into this vector as a selectable marker.

Another Sulfolobus-E. coli shuttle vector was described in 1998 (Cannio et al. 1998). The vector pEXSs is based on a part of the genome of the SSV1 cloned into pGEM5Zf(-) and contains a heterologous selectable marker gene coding for a thermostabilized version of the hygromycin phosphotransferase (Hph) from E. coli (Cannio et al. 2001). This vector was used to express a thermostable alcohol dehydrogenase from Bacillus stearothermophilus (Contursi et al. 2003), and to complement a lacS deletion mutant (S. solfataricus $\mathrm{G} \theta \mathrm{W}$ ) by expressing the genes lacS and lacTr coding for a $\beta$-glycosidase and a lactose transporter (Bartolucci et al. 2003).

Stedman et al. (1999) constructed a series of Sulfolobus$E$. coli shuttle vectors based on the complete genome of the virus SSV1. The vector pBluescript was inserted at different sites within the virus genome and constructs were identified that were not impaired in replication or infectivity. To one of these constructs the pyrEF genes from $S$. solfataricus $\mathrm{P} 2$ coding for orotatphosphoribosyl transferase and orotidine5 '-monophosphate decarboxylase were added as selectable marker. The expression of these marker genes allows for the complementation of uracil auxotroph recipients to uracil prototrophy. Additionally the lacS gene under control of the heat shock tf55 $\alpha$-promoter was cloned into the vector as a phenotypic marker. The resulting shuttle vector pMJ03 (Jonuscheit et al. 2003) replicates to high copy numbers in the primary transformation mixture as an episome. After plating and isolation of single transformants this vector was found to be integrated as a single copy into the chromosomal arginyl-tRNA gene of the recipient $S$. solfataricus PH1-16 (Martusewitsch et al. 2000) as previously observed for the wild type virus (Schleper et al. 1992). The pMJ03 vector was improved by Albers et al. (2006) by the development of preassembly constructs and an inducible promoter (see paragraph on promoters).

Another shuttle vector was based on the virus-plasmid hybrid pSSVx and the virus SSV2 (Arnold et al. 1999). Aucelli et al. (2006) developed a pSSVx-based vector that is spread in a culture by the help of the virus SSV2. The vector pMSSV was constructed from pSSVx and pUC19. 
No selectable marker is necessary for stable replication in Sulfolobus. It was nevertheless shown that the addition of the lac $S$ gene coding for a $\beta$-glycosidase was sufficient to complement the lacS deletion mutant $S$. solfataricus $\mathrm{G} \theta \mathrm{W}$.

Another Sulfolobus $-E$. coli vector system has been developed based on the plasmid pRN1 (Berkner et al. 2007). The vectors contain the $p y r E F$ genes for uracil selection in the pyrE deletion mutant $S$. acidocaldarius MR31 and the lacS gene for selection in S. solfataricus PBL2025. The $E$. coli vector part is a deletion derivative of pBluescript. Table 1 summarizes the different Sulfolobus-E. coli shuttle vectors published so far.

\section{Application of shuttle vectors}

With the shuttle vectors pDM1, pCSV1, as well as the different pAG constructs based on pGT5 no further experiments in Sulfolobus have been published. This is probably due to severe problems with the stability of these constructs (Aravalli and Garrett 1997; Stedman et al. 1999).

The vector pEXSs was used for protein expression and the cloning of a chromosomal replication origin in the same group (Bartolucci et al. 2003; Contursi et al. 2003, 2004), but this vector has to our knowledge never been used successfully outside of the developing laboratory. The thermostabilized Hph variant used in the pEXSs vector (Cannio et al. 2001) was shown to have only limited thermostability when tested in Thermus thermophilus (Nakamura et al. 2005).

The first shuttle vector that was successfully used in another than the developing laboratory, was the vector pMJ03 and derived constructs (Jonuscheit et al. 2003; Albers et al. 2006). This vector system has been used for promoter studies of the arabinose binding protein promoter (Lubelska et al. 2006), for the study of the replication operon of pRN1 (Berkner and Lipps 2007a), for the functional overexpression of the ABCE1 protein from S. solfataricus (Barthelme et al. 2007), for the study of the genes and proteins involved in bindosome assembly in $S$. solfataricus (Zolghadr et al. 2007) and for homologous overexpression of IF2 (Hasenöhrl et al. 2008). This vector system has the advantage of being self-spreading, thus circumventing the need for a high transformation efficiency, transformation frequency and efficient selection. A further benefit is the defined copy number of one for chromosomally integrated constructs that has advantages when using the construct in reporter gene assays. However, additional episomal vector copies were observed in some reporter gene experiments (Berkner and Lipps 2007a).

The large size of $22 \mathrm{~kb}$, the lack of unique restriction sites and repetitive sequences contained in the viral part of the vector render cloning with this construct rather difficult. To circumvent the high instability in standard E. coli cloning strains it is necessary to use specially designed E. coli strains to obtain plasmid preparations without rearranged plasmid products (Albers et al. 2006). The use of an intact virus also poses the risk of contaminating cultures kept in the same incubator shaker together with infected cultures. Furthermore the inefficient selection using the transposon mutant recipient strain $S$. solfataricus PH1-16 (see paragraph on selectable markers) is not always sufficient to promote the integration of the vector into the chromosome. In these cases no single transformants can be obtained (S. Berkner and G. Lipps, unpublished observations). Nevertheless the vector can be used for applications that do not necessarily require the integration into the chromosome. For complementation experiments and protein expression this system is well-suited because the primary transformation mixture can be used for transient expression, when the shuttle vector replicates in its episomal form to high copy numbers. Therefore the host range for this vector is not limited to the pyrEF/lacS double mutant $S$. solfataricus PH1-16 but can also be used with, e.g., S. solfataricus PBL2025 (Zolghadr et al. 2007), the only prerequisite being, that the recipient strain is a host for SSV1.

The shuttle vectors $\mathrm{pA}$ to $\mathrm{pN}$ based on the plasmid pRN1 have been used in three different laboratories. Using the lacS gene as a model it could be shown that expression of enzymes is possible in $S$. acidocaldarius and $S$. solfataricus (Berkner et al. 2007). In addition by cloning different promoter sequence upstream of the lacS gene the shuttle vectors could be used to determine the promoter strength in S. acidocaldarius (S. Berkner and G. Lipps, unpublished). The series of shuttle vectors $\mathrm{pA}-\mathrm{pN}$ has also been useful to analyze which of the six open reading frames found in the pRN1 plasmid are essential for replication. The experiments suggest that only the replication operon orf56/orf904 is required and indirect evidence indicates that Orf80 might be involved in plasmid partitioning (Berkner et al. 2007).

\section{Reporter genes}

Important tools for genetic experiments are reporter genes that help in translating the quantitative information on the expression level of a protein into an easily detectable signal. The only reporter gene used so far in Sulfolobus is the lac $S$ gene coding for a $\beta$-glycosidase that also shows $\beta$ galactosidase activity. $\beta$-galactosidase activity can be qualitatively detected using the substrate X-Gal (5-bromo-4chloro-3-indolyl- $\beta$-D-galactoside) that is converted to a blue colored product and can be detected readily on Gelrite plates. Quantitative determination of $\beta$-galactosidase activity by measuring the hydrolysis rate of ortho-nitrophenol- $\beta$ - 
D-galactopyranoside can also be performed in Sulfolobus crude extracts (Jonuscheit et al. 2003; Lubelska et al. 2006; Aucelli et al. 2006; Berkner and Lipps 2007a, Berkner et al. 2007).

For $S$. solfataricus and $S$. islandicus only mutants with inactivated or deleted lacS genes can serve as recipient strains for lac $S$ expressing constructs because the high level of endogenous $\beta$-galactosidase activity interferes with the reporter gene activity. S. acidocaldarius however only shows negligible endogenous $\beta$-galactosidase activity and can be used for reporter gene studies with an intact copy of the wild type lacS gene (Berkner et al. 2007).

The use of other reporter genes, e.g., fluorescent proteins that have proven to be extremely useful for the study of proteins in mesophilic organisms would also be desirable for Sulfolobus. Expression constructs containing a variant of the green fluorescent protein did not yield fluorescent signals in Sulfolobus (S. Berkner and G. Lipps, unpublished results).

\section{Promoters and affinity tags used for protein expression in Sulfolobus}

For expression purposes the promoter of the aspartate aminotransferase (aat, Cannio et al. 1998), the promoter of the $\alpha$-subunit of the thermosome (tf55 $\alpha$, Jonuscheit et al. 2003) and the promoter of the arabinose binding protein (araS, Lubelska et al. 2006; Albers et al. 2006) from S. solfataricus $\mathrm{P} 2$ have been used. The tf $55 \alpha$-promoter has a strong basal activity and is further inducible upon heat shock with high induction levels being reached $90 \mathrm{~min}$ after heat shock (Jonuscheit et al. 2003). The araS-promoter is inducible by addition of $0.2 \%$ arabinose to the growth medium. The expression of several proteins has been demonstrated using this promoter with yields of up to $1 \mathrm{mg}$ of protein from 11 of Sulfolobus culture (Albers et al. 2006).

For the straightforward expression and purification of proteins from Sulfolobus, affinity tags have been proven useful. Affinity tags tested so far are the strep-tag and purification over a streptactin column and a hexa- to decahistidine tag and purification over Ni-NTA columns. For strep-tagged proteins co-purification of biotinylated proteins from Sulfolobus crude extracts did sometimes interfere with purification. C-terminally his-tagged proteins could be readily purified from S. solfataricus and S. acidocaldarius crude extracts (Albers et al. 2006; S. Berkner and G. Lipps, unpublished results).

\section{Conclusions}

In recent years a number of genetic tools have been developed for Sulfolobus that now allow to perform genetic experiments in this interesting model organism. For $S$. solfataricus a variety of genetic tools is available, knockout systems as well as shuttle vectors. Vectors for $S$. solfataricus and the genetically more stable $S$. acidocaldarius have been developed and the ability of this organism for homologous recombination has already been demonstrated.

Despite the recent developments there is still a need for further improvements of genetic systems in Sulfolobus. For example, an inducible promoter with very low basal activity or a repressible promoter would allow for controlled expression of proteins. Furthermore knockout systems for $S$. acidocaldarius are urgently needed. Fluorescent reporter proteins would be very helpful for studies of protein localization in vivo. The development and improvement of further selection techniques would help to build more sophisticated genetic tools, e.g., two compatible shuttle replicons with different types of selection for simultaneous use in one recipient.

Acknowledgments This work was supported by the DFG (grant Li 913/3 to G.L.) in the framework of the Schwerpunktprogramm "Archaea".

\section{References}

Aagaard C, Phan H, Trevisanato S, Garrett RA (1994) A spontaneous point mutation in the single $23 \mathrm{~S}$ rRNA gene of the thermophilic archaeon Sulfolobus acidocaldarius confers multiple drug resistance. J Bacteriol 176:7744-7747

Aagaard C, Dalgaard JZ, Garrett RA (1995) Intercellular mobility and homing of an archaeal rDNA intron confers a selective advantage over intron-cells of Sulfolobus acidocaldarius. Proc Natl Acad Sci USA 92:12285-12289

Aagaard C, Leviev I, Aravalli RN, Forterre P, Prieur D, Garrett RA (1996) General vectors for archaeal hyperthermophiles: strategies based on a mobile intron and a plasmid. FEMS Microbiol Rev 18:93-104

Agron PG, Sobecky P, Andersen GL (2002) Establishment of uncharacterized plasmids in Escherichia coli by in vitro transposition. FEMS Microbiol Lett 217:249-254

Albers SV, Driessen AJM (2007) Conditions for gene disruption by homologous recombination of exogenous DNA into the Sulfolobus solfataricus genome. Archaea $2: \mathrm{i}-\mathrm{v}$

Albers SV, Jonuscheit M, Dinkelaker S, Urich T, Kletzin A, Tampé R, Driessen AJM, Schleper C (2006) Production of recombinant and tagged proteins in the hyperthermophilic archaeon Sulfolobus solfataricus. Appl Environ Microbiol 72:102-111

Allers T, Mevarech M (2005) Archaeal genetics-the third way. Nat Rev Genet 6:58-73

Andersson A, Lundgren M, Eriksson S, Rosenlund M, Bernander R, Nilsson P (2006) Global analysis of mRNA stability in the archaeon Sulfolobus. Genome Biol 7:R99

Aravalli RN, Garrett RA (1997) Shuttle vectors for hyperthermophilic archaea. Extremophiles 1:183-191

Arnold HP, She Q, Phan H, Stedman KM, Prangishvili D, Holz I, Kristiansson JK, Garrett RA, Zillig W (1999) The genetic element pSSVx of the extremely thermophilic crenarchaeon Sulfolobus is a hybrid between a plasmid and a virus. Mol Microbiol 34:217226 
Aucelli T, Contursi P, Girfoglio M, Rossi M, Cannio R (2006) A spreadable, non-integrative and high copy number shuttle vector for Sulfolobus solfataricus based on the genetic element pSSVx from Sulfolobus islandicus. Nucleic Acids Res 34:e114

Barry RC, Young MJ, Stedman KM, Dratz EA (2006) Proteomic mapping of the hyperthermophilic and acidophilic archaeon Sulfolobus solfataricus $\mathrm{P} 2$. Electrophoresis 27(14):2970-2983

Barthelme D, Scheele U, Dinkelaker S, Janoschka A, Macmillan F, Albers SV, Driessen AJ, Stagni MS, Bill E, Meyer-Klaucke W, Schünemann V, Tampé R (2007) Structural organization of essential iron-sulfur clusters in the evolutionarily highly conserved ATP-binding cassette protein ABCE1. J Biol Chem 282(19):14598-14607

Bartolucci S, Rossi M, Cannio R (2003) Characterization and functional complementation of a nonlethal deletion in the chromosome of a beta-glycosidase mutant of Sulfolobus solfataricus. J Bacteriol 185:3948-3957

Beck K, Lipps G (2007) Properties of an unusual DNA primase from an archaeal plasmid. Nucleic Acids Res 35:5635-5645

Bell SD, Jaxel C, Nadal M, Kosa PF, Jackson SP (1998) Temperature, template topology, and factor requirements of archaeal transcription. Proc Natl Acad Sci USA 95:15218-15222

Berkner S, Lipps G (2007a) Characterization of the transcriptional activity of the cryptic plasmid pRN1 from Sulfolobus islandicus REN1H1 and regulation of its replication operon. J Bacteriol 189:1711-1721

Berkner S, Lipps G (2007b) An active nonautonomous mobile element in Sulfolobus islandicus REN1H1. J Bacteriol 189:2145-2149

Berkner S, Lipps G (2008) Mutation and reversion frequencies of different Sulfolobus species and strains. Extremophiles 12:263-270

Berkner S, Grogan DW, Albers SV, Lipps G (2007) Small multicopy, non-integrative shuttle vectors based on the plasmid pRN1 for Sulfolobus acidocaldarius and Sulfolobus solfataricus, model organisms of the (cren-)archaea. Nucleic Acids Res 449:1-12. doi:10.1093/nar/gkm

Bini E, Dikshit V, Dirksen K, Drozda M, Blum P (2002) Stability of mRNA in the hyperthermophilic archaeon Sulfolobus solfataricus. RNA 8:1129-1136

Blount ZD, Grogan DW (2005) New insertion sequences of Sulfolobus: functional properties and implications for genome evolution in hyperthermophilic archaea. Mol Microbiol 55:312-325

Brock TD, Brock KM, Belly RT, Weiss RL (1972) Sulfolobus: a new genus of sulfur-oxidizing bacteria living at low $\mathrm{pH}$ and high temperature. Arch Microbiol 84:54-68

Brügger K, Redder P, She Q, Confalonieri F, Zivancovic Y, Garrett RA (2002) Mobile elements in archaeal genomes. FEMS Microbiol Lett 206:131-141

Brügger K, Torarinsson E, Redder P, Chen L, Garrett RA (2004) Shuffling of Sulfolobus genomes by autonomous and non-autonomous mobile elements. Biochem Soc Trans 32:179-183

Cammarano P, Teichner A, Londei P, Acca M, Nicolaus B, Sanz JL, Amils R (1985) Insensitivity of archaebacterial ribosomes to protein synthesis inhibitors. Evolutionary implications. EMBO J 4:811-816

Cannio R, Contursi P, Rossi M, Bartolucci S (1998) An autonomously replicating transforming vector for Sulfolobus solfataricus. J Bacteriol 180:3237-3240

Cannio R, Contursi P, Rossi M, Bartolucci S (2001) Thermoadaption of a mesophilic hygromycin B phosphotransferase by directed evolution in hyperthermophilic Archaea: selection of a stable genetic marker for DNA transfer into Sulfolobus solfataricus. Extremophiles 5:153-159

Chen L, Brügger K, Skovgaard M, Redder P, Qunxin S, Torarinsson E, Greve B, Awayez M, Zibat A, Klenk H-P, Garrett RA (2005) The genome of Sulfolobus acidocaldarius, a model organism of the Crenarchaeota. J Bacteriol 187:4992-4999
Chong PK, Wright PC (2005) Identification and characterization of the Sulfolobus solfataricus $\mathrm{P} 2$ proteom. J Proteome Res 4:1789-1798

Clore AJ, Stedman KM (2006) The SSV1 viral integrase is not essential. Virology 361:103-111

Condo I, Ciammaruconi A, Benelli D, Ruggero D, Londei P (1999) Cisacting signals controlling translational initiation in the thermophilic archaeon Sulfolobus solfataricus. Mol Microbiol 34:377-384

Contursi P, Cannio R, Prato S, Fiorentino G, Rossi M, Bartolucci S (2003) Development of a genetic system for hyperthermophilic Archaea: expression of a moderate thermophilic bacterial alcohol dehydrogenase gene in Sulfolobus solfataricus. FEMS Microbiol Lett 218:115-120

Contursi P, Pisani FM, Grigoriev A, Cannio R, Bartolucci S, Rossi M (2004) Identification and autonomous replication capability of a chromosomal replication origin from the archaeon Sulfolobus solfataricus. Extremophiles 8:385-391

Cubellis MV, Rozzo C, Montecucchi P, Rossi M (1990) Isolation and sequencing of a new beta-galactosidase-encoding archaebacterial gene. Gene 94:91-94

Duggin IG, Bell SD (2006) The chromosome replication machinery of the archaeon Sulfolobus solfataricus. J Biol Chem 281:1502915032

Fröls S, Gordon PM, Panlilio MA, Schleper C, Sensen CW (2007) Elucidating the transcription cycle of the UV-inducible hyperthermophilic archaeal virus SSV1 by DNA microarrays. Virology 365:48-59

Garrett RA, Redder P, Greve B, Brügger K, Chen L, She Q (2004) Archaeal plasmids. In: Funnel BE, Philips GJ (eds) Plasmid biology. ASM Press, Washington, pp 377-391

Grogan DW (1989) Phenotypic characterization of the archaebacterial genus Sulfolobus: comparison of five wild-type strains. J Bacteriol 171:6710-6719

Grogan DW (1991a) Selectable mutant phenotypes of the extremely thermophilic archaebacterium Sulfolobus acidocaldarius. J Bacteriol 173:7725-7727

Grogan DW (1991b) Evidence that beta-galactosidase of Sulfolobus solfataricus is only one of several activities of a thermostable beta-d-glycosidase. Appl Environ Microbiol 57:1644-1649

Grogan DW (1996) Exchange of genetic markers at extremely high temperatures in the archaeon Sulfolobus acidocaldarius. J Bacteriol 178:3207-3211

Grogan DW (2003) Cytosine methylation by the SuaI restriction-modification system: implications for genetic fidelity in a hyperthermophilic archaeon. J Bacteriol 185:4657-4661

Grogan DW, Gunsalus RP (1993) Sulfolobus acidocaldarius synthesizes UMP via a standard de novo pathway: results of a biochemical-genetic study. J Bacteriol 175:1500-1507

Grogan D, Palm P, Zillig W (1990) Isolate B12, which harbours a virus-like element, represents a new species of the archaebacterial genus Sulfolobus, Sulfolobus shibatae, sp. nov. Arch Microbiol 154:594-599

Grogan DW, Carver GT, Drake JW (2001) Genetic fidelity under harsh conditions: analysis of spontaneous mutation in the thermoacidophilic archaeon Sulfolobus acidocaldarius. Proc Natl Acad Sci USA 98:7928-7933

Hansen JE, Dill AC, Grogan DW (2005) Conjugational genetic exchange in the hyperthermophilic archaeon Sulfolobus acidocaldarius: intragenic recombination with minimal dependence on marker separation. J Bacteriol 187(2):805-809

Hasenöhrl D, Lombo T, Kaberdin V, Londei P, Bläsi U (2008) Translation initiation factor a/eIF $2 \gamma$ counteracts $5^{\prime}$ to $3^{\prime}$ mRNA decay in the archaeon Sulfolobus solfataricus. Proc Natl Acad Sci USA 105:2146-2150

Hjort K, Bernander R (2001) Cell cycle regulation in the hyperthermophilic crenarchaeon Sulfolobus acidocaldarius. Mol Microbiol $40: 225-234$ 
Huber H, Prangishvili D (2006) Sulfolobales. In: Dworkin M, Falkow S, Rosenberg E, Schleifer K-H, Stackebrandt E (eds) Prokaryotes. Springer, New York, pp 23-51

Jonuscheit M, Martusewitsch E, Stedman KM, Schleper C (2003) A reporter gene system for the hyperthermophilic archaeon Sulfolobus solfataricus based on a selectable and integrative shuttle vector. Mol Microbiol 48:1241-1252

Keeling PJ, Klenk H-P, Singh RK, Feeley O, Schleper C, Zillig W, Doolittle WF, Sensen CW (1996) Complete nucleotide sequence of the Sulfolobus islandicus multicopy plasmid pRN1. Plasmid 35:141-144

Keeling PJ, Klenk H-P, Singh RK, Schenk ME, Sensen CW, Zillig W, Doolittle WF (1998) Sulfolobus islandicus plasmids pRN1 and pRN2 share distant but common evolutionary ancestry. Extremophiles 2:391-393

Kletzin A, Lieke A, Urich T, Charlebois RL, Sensen CW (1999) Molecular Analysis of pDL10 from Acidianus ambivalens reveals a family of related plasmids from extremly thermophilic and acidophilic Archaea. Genetics 152:1307-1314

Kondo S, Yamagishi A, Oshima T (1991) Positive selection for uracil auxotrophs of the sulfur-dependent thermophilic archaebacterium Sulfolobus acidocaldarius by use of 5-fluoroorotic acid. J Bacteriol 173:7698-7700

Korencic D, Ahel I, Schelert J, Sacher M, Ruan B, Stathopoulos C, Blum P, Ibba M, Söll D (2004) A freestanding proofreading domain is required for protein synthesis quality control in Archaea. Proc Natl Acad Sci USA 101:10260-10265

Kurosawa N, Grogan DW (2005) Homologous recombination of exogenous DNA with the Sulfolobus acidocaldarius genome: properties and uses. FEMS Microbiol Lett 253:141-149

Lipps G (2006) Plasmids and viruses of the thermoacidophilic crenarchaeote Sulfolobus. Extremophiles 10:17-28

Lipps G (2007) Plasmids. In: Garrett RA, Klenk H-P (eds) Archaea: evolution, physiology and molecular biology. Oxford, UK

Lipps G, Stegert M, Krauss G (2001a) Thermostable and site-specific DNA binding of the gene product ORF56 from the Sulfolobus islandicus plasmid pRN1, a putative archael plasmid copy control protein. Nucleic Acids Res 29:904-913

Lipps G, Ibanez P, Stroessenreuther T, Hekimian K, Krauss G (2001b) The protein ORF80 from the acidophilic and thermophilic archaeon Sulfolobus islandicus binds highly site-specifically to doublestranded DNA and represents a novel type of basic leucine zipper protein. Nucleic Acids Res 29:4973-4982

Lipps G, Röther S, Hart C, Krauss G (2003) A novel type of replicative enzyme harboring ATPase, primase and DNA polymerase activity. EMBO J 22:2516-2525

Lipps G, Weinzierl AO, von Scheven G, Buchen C, Cramer P (2004) Structure of a bifunctional DNA primase-polymerase. Nat Struct Mol Biol 11:157-162

Lubelska JM, Jonuscheit M, Schleper C, Albers SV, Driessen AJ (2006) Regulation of expression of the arabinose and glucose transporter genes in the thermophilic archaeon Sulfolobus solfataricus. Extremophiles 10:383-391

Lundgren M, Bernander R (2007) Genome-wide transcription map of an archaeal cell cycle. Proc Natl Acad Sci USA 104:2939-2944

Martusewitsch E, Sensen CW, Schleper C (2000) High spontaneous mutation rate in the hyperthermophilic archaeon Sulfolobus solfataricus is mediated by transposable elements. J Bacteriol 182:2574-2581

Muskhelishvili G, Palm P, Zillig W (1993) SSV1-encoded site-specific recombination system in Sulfolobus shibatae. Mol Gen Genet 237:334-342

Nakamura A, Takakura Y, Kobayashi H, Hoshino T (2005) In vivo directed evolution for thermostabilization of Escherichia coli hygromycin B phosphotransferase and the use of the gene as a selection marker in the host-vector system of Thermus thermophilus. J Biosci Bioeng 100:158-163

Norais C, Hawkins M, Hartmann AL, Eisen JA, Myllykallio H, Allers $\mathrm{T}$ (2007) Genetic and physical mapping of DNA replication origins in Haloferax volcanii. PLoS Genet 3:e77

Peng X, Holz I, Zilling W, Garrett RA, She Q (2000) Evolution of the family of $\mathrm{pRN}$ plasmids and their integrase-mediated insertion into the chromosome of the Crenarchaeon Sulfolobus solfataricus. J Mol Biol 303:449-454

Prangishvili D, Garrett RA (2005) Viruses of hyperthermophilic Crenarchaea. Trends Microbiol 13:535-542

Prangishvili DA, Vashakidze RP, Chelidze MG, Gabriadze IY (1985) A restriction endonuclease $S u a$ I from the thermoacidophilic archaebacterium Sulfolobus acidocaldarius. FEBS Lett 192:57-60

Prangishvili D, Stedman K, Zillig W (2001) Viruses of the extremely thermophilic archaeon Sulfolobus. Trends Microbiol 9:39-43

Purschke WG, Schäfer G (2001) Independent replication of the plasmids pRN1 and pRN2 in the archaeon Sulfolobus islandicus. FEMS Microbiol Lett 200:97-102

Redder P, Garrett RA (2006) Mutations and rearrangements in the genome of Sulfolobus solfataricus P2. J Bacteriol 188:41984206

Reilly MS, Grogan DW (2001) Characterizatin of intragenic recombination in a hyperthermophilic archaeon via conjugational DNA exchange. J Bacteriol 183:2943-2946

Reilly MS, Grogan DW (2002) Biological effects of DNA damage in the hyperthermophilic archaeon Sulfolobus acidocaldarius. FEMS Microbiol Lett 208:29-34

Reiter WD, Palm P, Zillig W (1988) Analysis of transcription in the archaebacterium Sulfolobus indicates that archaebacterial promoters are homologous to eukaryotic pol II promoters. Nucleic Acids Res 16:1-19

Ruggero D, Londei P (1996) Differential antibiotic sensitivity determined by the large ribosomal subunit in thermophilic Archaea. J Bacteriol 178:3396-3398

Sanz JL, Huber G, Huber H, Amils R (1994) Using protein synthesis inhibitiors to establish the phylogenetic relationships of the Sulfolobales order. J Mol Evol 39:528-532

Sartorius-Neef S, Pfeifer F (2004) In vivo studies on putative ShineDalgarno sequences of the halophilic archaeon Halobacterium salinarum. Mol Microbiol 51:579-588

Schelert J, Dixit V, Hoang V, Simbahan J, Drozda M, Blum P (2004) Occurence and characterization of mercury resistance in the hyperthermophilic archaeon Sulfolobus solfataricus by use of gene disruption. J Bacteriol 186:427-437

Schleper C (1993) Genetische Elemente und Transformation des extrem thermophilen Archaeons Sulfolobus solfataricus, $\mathrm{PhD}$ thesis, Fakultät für Biologie, Ludwig-Maximilians-Universität, München, Germany

Schleper C, Kubo K, Zillig W (1992) The particle SSV1 from the extremely thermophilic archaeon Sulfolobus is a virus: demonstration of infectivity and of transfection with the viral DNA. Proc Natl Acad Sci USA 89:7645-7649

Schleper C, Roder R, Singer T, Zillig W (1994) An insertion element of the extremely thermophilic archaeon Sulfolobus solfataricus transposes into the endogenous beta-galactosidase gene. Mol Gen Genet 243:91-96

She Q, Singh RK, Confalonieri F, Zivanovic Y, Allard G, Awayez MJ, Chan-Weiher CC, Clausen IG, Curtis BA, De Moors A, Erauso G, Fletcher C, Gordon PM, Heikamp-de Jong I, Jeffries AC, Kozera CJ, Medina N, Peng X, Thi-Ngoc HP, Redder P, Schenk ME, Theriault C, Tolstrup N, Charlebois RL, Doolittle WF, Duguet M, Gaasterland T, Garrett RA, Ragan MA, Sensen CW, Van der Oost J (2001) The complete genome of the crenarchaeon Sulfolobus solfataricus P2. Proc Natl Acad Sci USA 98:7835-7840 
Snijders AP, Walther J, Peter S, Kinnman I, de Vos MG, van de Werken HJ, Brouns SJ, van der Oost J, Wright PC (2006) Reconstruction of central carbon metabolism in Sulfolobus solfataricus using a two-dimensional gel electrophoresis map, stable isotope labelling and DNA microarray analysis. Proteomics 6(5):1518-1529

Söllner S, Berkner S, Lipps G (2006) Characterisation of the novel restriction endonuclease SuiI from Sulfolobus islandicus. Extremophiles 10:629-634

Stedman KM, Schleper C, Rumpf E, Zillig W (1999) Genetic requirements for the function of the archeal virus SSV1 in Sulfolobus solfataricus: construction and testing of a viral shuttle vector. Genetics 152:1397-1405

Suzuki T et al. (2002) Sulfolobus tokodaii sp. nov. (f. Sulfolobus sp. strain 7), a new member of the genus Sulfolobus isolated from Beppu Hot Springs, Japan. Extremophiles 6:39-44

Szabo Z, Sani M, Groeneveld M, Zolghadr B, Schelert J, Albers SV, Blum P, Boekema EJ, Driessen AJM (2007) Flagellar motility and structure in the hyperthermoacidophilic Archaeon Sulfolobus solfataricus. J Bacteriol 189:4305-4309

Worthington P, Hoang V, Perez-Pomares F, Blum P (2003) Targeted disruption of the alpha-amylase gene in the hyperthermophilic Archaeon Sulfolobus solfataricus. J Bacteriol 185:482-488
Yeats S, McWilliam P, Zillig W (1982) A plasmid in the archaebacterium Sulfolobus acidocaldarius. EMBO J 1:1035-1038

Zillig W, Kletzin A, Schleper C, Holz I, Janekovic D, Hain J, Lanzendörfer M, Kristiansson JK (1994) Screening for Sulfolobales, their plasmids, and their viruses in Islandic solfataras. Syst Appl Microbiol 16:606-628

Zillig W, Prangishvili D, Schleper C, Elferink MGL, Holz I, Albers S, Janekovic D, Götz D (1996) Viruses, plasmids and other genetic elements of thermophilic and hyperthermophilic Archaea. FEMS Microbiol Rev 18:225-236

Zillig W, Arnold HP, Holz I, Prangishvili D, Schweier A, Stedman K, She Q, Phan H, Garrett RA, Kristiansson JK (1998) Genetic elements in the extremely thermophilic archaeon Sulfolobus. Extremophiles 2:131-140

Zolghadr B, Weber S, Szabó Z, Driessen AJ, Albers SV (2007) Identification of a system required for the functional surface localization of sugar binding proteins with class III signal peptides in Sulfolobus solfataricus. Mol Microbiol 64(3):795-806 